\title{
Analysis of yield stability of malt barley genotypes under terminal moisture stressed areas of North Wollo, Ethiopia
}

\author{
Arega Gashaw*, Agegnehu Mekonnen and Akalu Gebru \\ Sirinka Agricultural Research Center, North Wollo, P.O. Box 74 Woldia, Ethiopia. \\ *Corresponding author. Email: argonlacomolza@gmail.com
}

Copyright @ 2019 Gashaw et al. This article remains permanently open access under the terms of the Creative Commons Attribution License 4.0, which permits unrestricted use, distribution, and reproduction in any medium, provided the original work is properly cited.

Received 3rd January, 2019; Accepted 19th February, 2019

\begin{abstract}
Field experiments were conducted at Estayish, Geregera and Kon testing sites of Sirinka Agricultural Research Center (SARC), North Wollo, Ethiopia for two consecutive years (2013 and 2014) during the main season with the objective of evaluating the performance of malt barley genotypes for grain yield and yield stability under diverse environments. Fifteen promising malt barley genotypes, along with the standard check (Miscal 21) were evaluated using Randomized Complete Block Design (RCBD), replicated three times. Genotypes were row-planted on a plot size of $3 \mathrm{~m}^{2}$. $\mathrm{N}$ and $\mathrm{P}_{2} \mathrm{O}_{5}$, in the form of Urea and Di-Ammonium Phosphate (DAP) fertilizers, were applied at the rate of $23 \mathrm{~kg} \mathrm{ha}^{-1}$ and $46 \mathrm{~kg} \mathrm{ha}^{-1}$, respectively and all other cultural practices were carried-out uniformly for all treatments as required. Grain yield was recorded from the central four rows $\left(2 \mathrm{~m}^{2}\right)$ and measured with sensitive balance. Data were subjected to analysis of variance (ANOVA) using Genstat software package 16th edition. Duncan Multiple Range Test (DMRT) was used to separate means. Genotype by Genotype-Environment (GGE) biplot model was employed to analyze phenotypic stability of malt barley genotypes for grain yield. ANOVA depicted significant variations $(p<0.01)$ among genotypes $(G)$, years $(Y)$, locations $(L)$ and their two and three way interactions for grain yield. The presence of significant variations among the tested malt barley genotypes for grain yield indicated the possibility of improving productivity of malt barley through selection. However, the existence Genotype x Environment Interaction (GEI) revealed differential response of malt barley genotype across environments, necessitating to develop environmentally less sensitive malt barley genotype. Analysis of GGE revealed that $\mathrm{G}_{6}$ and $\mathrm{G}_{11}$ were close to the ideal genotype and hence recommended for major barley producing areas of North Wollo.
\end{abstract}

Keywords: Genotype x Environment Interaction, Genotype by Genotype-Environment, malt barley, principal component analysis, stability.

\section{INTRODUCTION}

Barley (Hordeum vulgare L.) is the major cool seasoned cereal crop in North Wollo, covering about $16.6 \%$ (35,737 ha) of arable land allocated for cereal crops production. About 477, 420 quintal (qt) of barley grains (constituting $16.6 \%$ of cereal grain production share) is annually produced (CSA, 2016). Malt barley is a recent introduction to Ethiopian farming system and information of total malt barley production coverage and production is lump summed with food barley.

Malt barley is one of the major ingredients in brewing industries. Breweries are booming in Ethiopia, demanding more than 2.3 million quintals of malt barley grains per annum (Bantayehu, 2013). However, production of malt barley was very low in the country and did not satisfy the local breweries annual malt barley grains demand. Thus, breweries are obliged to import malt barley grains with hard currency to augment local production. About $62 \%$ of the total annual malt barley grains demand was covered through importation. The demand for malt barley grains in international and national markets is increasing. The high demand for malt barley grains in local market is a good opportunity for resource poor farmers that have no or very 
limited marketable goods to generate income and improve their livelihoods.

Regardless of the agro-ecological suitability for malt barley cultivation in Eastern Amhara, production of malt barley remains very low. Agricultural Transformation Agency (ATA) of Ethiopia identified and delineated Meqdella-Gimba cluster as the major malt barley producing zone in Eastern Amhara. This cluster comprised ten major barley producing districts of South Wollo that able to supply malt barley grains for the growing brewing industries. Developing and introducing high yielding and stable malt barley varieties possessing acceptable malting quality traits to farmers is very crucial to improve malt barley production and produc-tivity and thereby substitute imported malt barley grains.

Development of high yielding and stable varieties is the primary target of any plant breeders. Grain yield, a complex polygenic trait, exhibits Genotype x Environment Interactions (GEI) (Fan et al., 2007). The existence of GEI is a major problem for the breeders in making reliable estimate of the performances of genotypes (Akçura et al., 2009; Ilker et al., 2018) and complicates the identification of superior genotypes for a range of environments (Ding et al., 2007; Kadhem and Baktash, 2016; Karimizadeh et al., 2013). GEI reduces the correlation between phenotype and genotype values, resulting inconsistent performance of genotypes in different environments and decreases selection efficiency (Kang, 1997; Karimizadeh et al., 2013). Hence, identifying genotypes that perform relatively consistent across diverse environments or specifically adapted genotypes to defined environment would minimizes performance inconsistencies. However, information on GEI of malt barley genotypes to diverse environments at moisture stressed areas of North Wollo is lacking. Hence, evaluation of malt barley genotypes at diverse environments could provide useful information to identify high yielding and stable genotype.

Several statistical models have been proposed to analyze GEI and stability of genotypes in multienvironment trial (MET) (Ding et al., 2007; Karimizadeh et al., 2013; Yan et al., 2007). Of the various stability models, Genotype by Genotype-Environment interaction (GGE) biplot (Ding et al., 2007; Karimizadeh et al., 2013; Yan and Tinker, 2006) is the most recent and efficient stability analytical tool. GGE biplot models is powerful in determining the most stable and high yielding genotypes in MET. GGE captures a large portion of the GEI sum of squares (Agyeman et al., 2015; Oliveira et al., 2014) and can clearly summarize patterns and relationships of genotypes and environments (Kadhem and Baktash, 2016; Oliveira et al., 2014). GGE uses interaction Principal Component (PC) analysis and became a popular data visualization tool (Karimizadeh et al., 2013; Yan et al., 2007). It graphically displays the results in a very informative way and clearly generates information on specific and widely adapted genotypes (Agyeman et al., 2015; Oliveira et al., 2014; Yan et al., 2007). The objective of this experiment was, therefore, to evaluate the perfor- mance and stability of malt barley genotypes at diverse and moisture stressed areas of North Wollo using GGE biplot statistical mode.

\section{MATERIALS AND METHODS}

\section{Description of the study area}

Field experiments were conducted at Estayish, Geregera and Kon testing sites of Sirinka Agricultural Research Center (SARC), North Wollo Administrative zone, Ethiopia during 2013 and 2014 cropping seasons under rain-fed condition. Estayish, Geregera and Kon testing sites are located at 580, 660 and 642 kilometers North East of the capital city, Addis Ababa, respectively. The highland areas of North Wollo received uni-modal rainfall pattern. The testing sites are generally characterized as terminal moisture stressed environments: late onset (during planting time), early termination (during critical grain filling period), and occasionally torrential rainfall followed by long dry spells are the major and common problems of the farming community (Gashaw et al., 2010). Description of the testing sites is presented in Table 1.

\section{Plant materials and experimental design}

Fifteen malt barley genotypes (Table 2), along with standard check (Miscal 21) were evaluated for grain yield and yield stability across diverse environments. The experiment was carried-out in Randomized Complete Block Design (RCBD) replicated three times. The genotypes were row planted at a seed rate of $85 \mathrm{~kg} \mathrm{ha}^{-1}$. A plot size of $3 \mathrm{~m}^{2}$ (six rows of $2.5 \mathrm{~m}$ length with an interrow spacing of $0.2 \mathrm{~m}$ ) was used.

\section{Experimental procedure}

Nitrogen and phosphorous fertilizers were applied in the form of Urea $(46 \% \mathrm{~N})$ and Di-Ammonium Phosphate (DAP) $\left(18 \% \mathrm{~N}\right.$ and $\left.46 \% \mathrm{P}_{2} \mathrm{O}_{5}\right)$ at the rate of 23 and $46 \mathrm{~kg}$ ha $^{-1}$, respectively. Full dose of $\mathrm{P}_{2} \mathrm{O}_{5}$ were applied at planting time, while $\mathrm{N}$ was applied in split, half at planting time and the remaining half at tillering stage. The experiment was hand-weeded twice at 20 to 25 and 40 to 45 days after emergence and other management practices were done as required. Genotypes were row-planted on a plot size of $3 \mathrm{~m}^{2}$ (six rows with an inter-row spacing of 0.2 $\mathrm{m}$ and $2.5 \mathrm{~m}$ length).

\section{Data collection and statistical analysis}

Grain yield was measured as the total weight of clean grains from the central four rows (harvestable net plot size of $2 \mathrm{~m}^{2}$ ), leaving a border rows from both sides of the plot and measured with sensitive balance, adjusted at $12.5 \%$ seed moisture content. Data were subjected to analysis of 
Table 1. Description of the testing environments.

\begin{tabular}{lllcccc}
\hline \multirow{2}{*}{ Code } & \multirow{2}{*}{ Environments } & \multirow{2}{*}{ Soil type } & \multicolumn{2}{c}{ Geographical coordinates } & \multirow{2}{*}{ Rainfall ${ }^{*}(\mathbf{m m})$} \\
\cline { 4 - 6 } & & & Latitude & Longitude & Altitude (m.a.s.l) & \\
\hline $\mathrm{E}_{1}$ & Geregera-2013 & Litosol & $11^{\circ} 45^{\prime} 02^{\prime \prime} \mathrm{N}$ & $38^{\circ} 44^{\prime} 57^{\prime \prime} \mathrm{E}$ & 2872 & 1060 \\
$\mathrm{E}_{2}$ & Kon-2013 & Litosol & $11^{\circ} 36^{\prime} 51^{\prime \prime} \mathrm{N}$ & $38^{\circ} 55^{\prime} 29^{\prime \prime} \mathrm{E}$ & 2878 & 720 \\
$\mathrm{E}_{3}$ & Estayish-2013 & Litosol & $11^{\circ} 49^{\prime} 34^{\prime \prime} \mathrm{N}$ & $39^{\circ} 07^{\prime} 36^{\prime \prime} \mathrm{E}$ & 3271 & $\mathrm{NA}$ \\
$\mathrm{E}_{4}$ & Geregera-2014 & Litosol & $11^{\circ} 45^{\prime} 02^{\prime \prime} \mathrm{N}$ & $38^{\circ} 44^{\prime} 57^{\prime \prime} \mathrm{E}$ & 2872 & 904 \\
$\mathrm{E}_{5}$ & Kon-2014 & Litosol & $11^{\circ} 36^{\prime} 51^{\prime \prime} \mathrm{N}$ & $38^{\circ} 55^{\prime} 29^{\prime \prime} \mathrm{E}$ & 2878 & 605 \\
$\mathrm{E}_{6}$ & Estayish-2014 & Litosol & $11^{\circ} 49^{\prime} 34^{\prime \prime} \mathrm{N}$ & $39^{\circ} 07^{\prime} 36^{\prime \prime} \mathrm{E}$ & 3271 & $\mathrm{NA}$ \\
\hline
\end{tabular}

*Effective rainfall from June-October, $N A=$ not available.

Source: National Meteorology Agency, Kombolcha Meteorological Station, Kombolcha, Amhara (Ethiopia).

Table 2. Pedigree of tested malt barley genotypes.

\begin{tabular}{ll}
\hline Code & Pedigree \\
\hline$G_{1}$ & MSEL/CONLON \\
$G_{2}$ & CANELA/ESTANZUELA JACARANDA \\
$G_{3}$ & E.ACACIA/DEFRA//ATAH 92/GOB \\
$G_{4}$ & LIBRA T95/AF9216 \\
$G_{5}$ & IBCB_SPRING09/10\#115 \\
$G_{6}$ & LIBRA T95/DIAMALT \\
$G_{7}$ & MERIT,B/AC METCALFE \\
$G_{8}$ & BSI 58 \\
$G_{9}$ & IBL SGP09/10\#14 \\
$G_{10}$ & E.ACACIA/DEFRA/3/SVANHALS/BAR/MSEL//AZAF/GOB24DH \\
$G_{11}$ & E.ACACIA/DEFRA//ATAH92/GOB \\
$G_{12}$ & CONDOR-BAR/3/PTT.B/RUDA//ALELI/4/ALELI/5/FOSTER \\
$\mathrm{G}_{13}$ & FNC I 22/DEFRA/6/ZHEDAR\#1/4/SHYRI//GLORIA-BAR/COPAL/3/SHYRI/GRIT/5/ARUF \\
$\mathrm{G}_{14}$ & ND19929/PRISNA//CANELA \\
$\mathrm{G}_{15}$ & Miscal 21 \\
\hline
\end{tabular}

variance (ANOVA) using Genstat software package 16th edition. Duncan Multiple Range Test (DMRT) was used to separate means. Stability of genotypes across diverse environments was analyzed using Genotype by GenotypeEnvironment interaction (GGE) biplot model as described by Yan (2002), Yan and Hunt (2001) and Yan et al. (2007). The GGE biplot was constructed by plotting the first two principal components (PC1 and PC2) scores.

\section{RESULTS AND DISCUSSION}

\section{Descriptive analysis}

Before pooling the data, homogeneity of error variance was tested using Bartlett's test of homeogeneity of error variances (d Steel and Torrie, 1986). Bartlett's test of homeogeneity of error variances $(p<0.19)$ illustrated that grain yield data obtained from the six environments was homogeneous. Thus, it indicates the possibility of combining the data for analysis. Pooled analysis of variance (ANOVA) depicted highly significant variation $(p<0.01)$ among malt barley genotypes for grain yield (Table 3 ), indicating the opportunity of selecting high yielding genotypes. Moreover, genotype $x$ year $(G x Y)$, genotype $x$ location $(G \times L)$ and genotype $x$ year $x$ location ( $G x Y x L)$ interaction significantly varied $(p<0.01)$, implying differential response of genotypes across seasons and locations, necessitating to develop location-specific or stable malt barley genotype for the tested environments. Hence, developing high yielding and stable genotype would minimize genotypic performance inconsistencies at diverse environments and improve production and productivity of malt barley.

Mean grain yield of malt barley genotypes grown at six environments is presented in Table 4. It ranged from 140 $\mathrm{kg} \mathrm{ha}^{-1}$ (for $\mathrm{G}_{8}$ at Estayish 2013) to $3992 \mathrm{~kg} \mathrm{ha}^{-1}$ (for $\mathrm{G}_{6}$ at Kon 2014). $\mathrm{G}_{6}\left(2462 \mathrm{~kg} \mathrm{ha}^{-1}\right)$ consistently out-smarted in grain yield over the rest of the malt barley genotypes in most of the tested environments, followed by $\mathrm{G}_{2}(2345 \mathrm{~kg}$ $\mathrm{ha}^{-1}$ ) and $\mathrm{G}_{11}$ (2339 $\mathrm{kg} \mathrm{ha}^{-1}$ ). Erratic rainfall distribution, terminal moistures stress, soil acidity, low temperature and 
Table 3. Analysis of variance (ANOVA) of 15 malt barley genotypes evaluated at three Locations for two consecutive seasons.

\begin{tabular}{lcccc}
\hline Source of variation & Degree of freedom & Sum of square & Mean square & Probability \\
\hline Replication & 2 & 10211 & 5106 & \\
Genotype (G) & 14 & 13852727 & 989481 & $<0.001$ \\
Location (L) & 2 & 22074438 & 11037219 & $<0.001$ \\
Year (Y) & 1 & 119482481 & 119482481 & $<0.001$ \\
GXL & 28 & 14992125 & 535433 & $<0.001$ \\
GXY & 14 & 8874331 & 633881 & $<0.001$ \\
LXY & 2 & 10668061 & 5334031 & $<0.001$ \\
GXLXY & 28 & 15802234 & 564366 & $<0.001$ \\
Residual & 178 & 29754780 & 167162 & \\
Total & 269 & 235511388 & & \\
\hline
\end{tabular}

Table 4. Performance of malt barley genotypes for grain yield $\left(\mathrm{kg} \mathrm{ha}^{-1}\right)$ at Geregera, Kon and Estayish 2013 and 2014 cropping seasons.

\begin{tabular}{lccccccc}
\hline Code & $\mathbf{E}_{\mathbf{1}}$ & $\mathbf{E}_{\mathbf{2}}$ & $\mathbf{E}_{\mathbf{3}}$ & $\mathbf{E}_{\mathbf{4}}$ & $\mathbf{E}_{\mathbf{5}}$ & $\mathbf{E}_{6}$ & Mean \\
\hline $\mathrm{G}_{1}$ & 638 & 1055 & 567 & 2787 & 2575 & 2015 & 1606 \\
$\mathrm{G}_{2}$ & 1540 & 1471 & 1433 & 2440 & 3658 & $\underline{\mathbf{3 5 2 6}}$ & 2345 \\
$\mathrm{G}_{3}$ & 1297 & 1517 & 1133 & 2794 & 3172 & $\mathbf{2 0 9 9}$ & 2002 \\
$\mathrm{G}_{4}$ & 1286 & 1639 & 567 & 2285 & 3303 & 1288 & 1728 \\
$\mathrm{G}_{5}$ & 1495 & 1236 & 400 & 2872 & 2817 & 2657 & 1913 \\
$\mathrm{G}_{6}$ & 2082 & 2290 & 500 & $\underline{\mathbf{3 2 0 8}}$ & $\underline{\mathbf{3 9 9 2}}$ & 2699 & $\underline{\mathbf{2 4 6 2}}$ \\
$\mathrm{G}_{7}$ & 1778 & 2197 & 150 & 2210 & 2684 & 2405 & 1904 \\
$\mathrm{G}_{8}$ & 1611 & $\underline{\mathbf{2 3 7 3}}$ & 140 & 2192 & 3244 & 2797 & 2060 \\
$\mathrm{G}_{9}$ & 1829 & 1713 & 267 & 2372 & 3176 & 3084 & 2073 \\
$\mathrm{G}_{10}$ & $\underline{\mathbf{2 1 0 6}}$ & 2001 & 700 & 2128 & 2465 & 2459 & 1977 \\
$\mathrm{G}_{11}$ & 1894 & 1988 & 467 & 3132 & 3047 & 3504 & 2339 \\
$\mathrm{G}_{12}$ & 897 & 2314 & 1027 & 2166 & 2223 & 2354 & 1830 \\
$\mathrm{G}_{13}$ & 1583 & 1870 & $\underline{\mathbf{1 5 4 8}}$ & 2050 & 2328 & 2721 & 2017 \\
$\mathrm{G}_{14}$ & 1713 & 1609 & 492 & 2521 & 2353 & 2761 & 1908 \\
$\mathrm{G}_{15}$ & 1859 & 1468 & 1400 & 2824 & 2980 & 2640 & 2195 \\
$\mathrm{Mean}$ & 1574 & 1783 & 719 & 2532 & 2934 & 2601 & 2024 \\
\hline
\end{tabular}

poor soil fertility were the major and critical production constraints that significantly impedes barley production at North Wollo. The buffering capacity of malt barley genotypes to withstand varous abiotic stresses were significantly different. Genotype that consistently outsmarting in grain yield under variable edaphic and nonedaphic conditions explicitly showed its adptablity to the target environment. Thus, from this study, $\mathrm{G}_{6}$ was found adaptable and agronomically superior malt barley genotype under terminal moisture stressed environments of North Wollo. On the other hand, due to a relatively fair rainfall distribution in 2013 than 2014 cropping season, maximum mean grain yield was recorded at Kon 2014 (2934 kg ha-1) followed by Estayish $2014\left(2601 \mathrm{~kg} \mathrm{ha}^{-1}\right)$ and Geregera 2014 (2532 kg ha ${ }^{-1}$ ) indicating 2014 cropping season was conducive environment for malt barley production.

\section{GGE biplot analysis}

Genotype by Environment Interaction (GEI) sum square was partitioned into principal component analysis axes. The first two principal component analysis axes (PC1 and PC2) were commonly used (Ilker et al., 2010). Accordingly, GEl sum square was partitioned to PC1 and PC2 and plotted in GGE biplot graph. The x-axis represents PC1 values denoting yielding potential of genotypes and environments while $y$-axis corresponds to PC2 values designating the interaction of genotypes at variable environments. PC1 and PC2 explained $32.89 \%$ and $24.8 \%$, respectively for grain yield, accounting $57.69 \%$ of the total variations (Figure 1). The performance and interaction of malt barley genotypes for grain yield across diverse environments (Figure 1), " which-won-where" and classifycation of mega-environments (Figure 2), identification of 


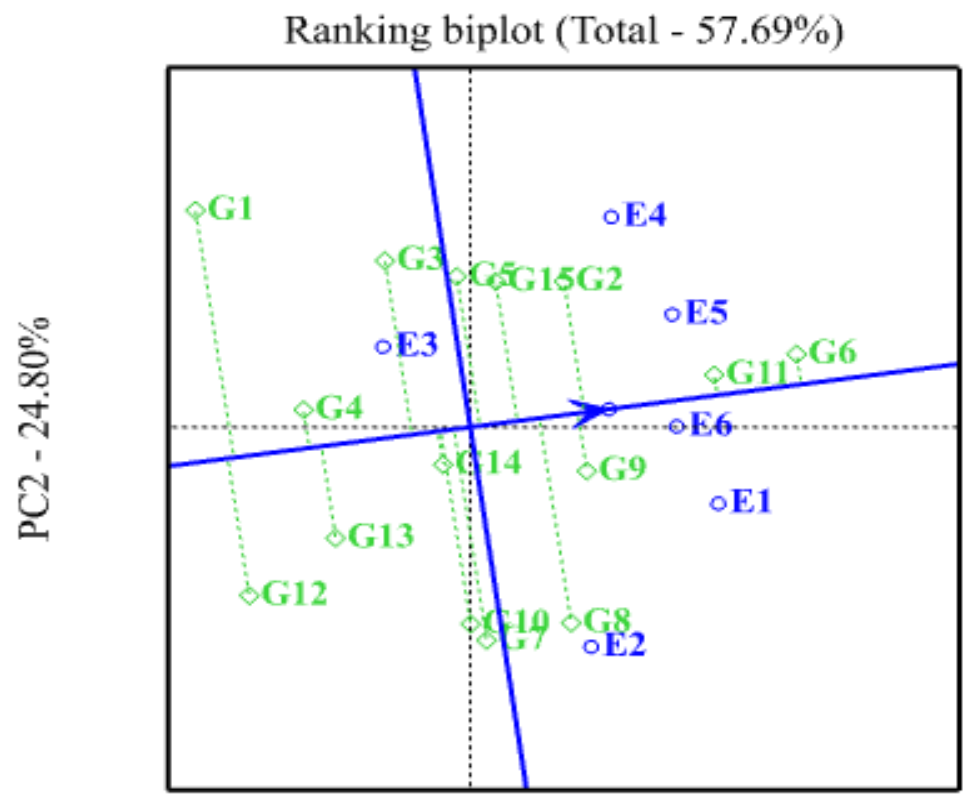

$$
\text { PC1 - 32.89\% }
$$

Genotype scores

Environment scores

- AEC

Figure 1. Performance and grain yield stability of malt barley genotypes across diverse environments.

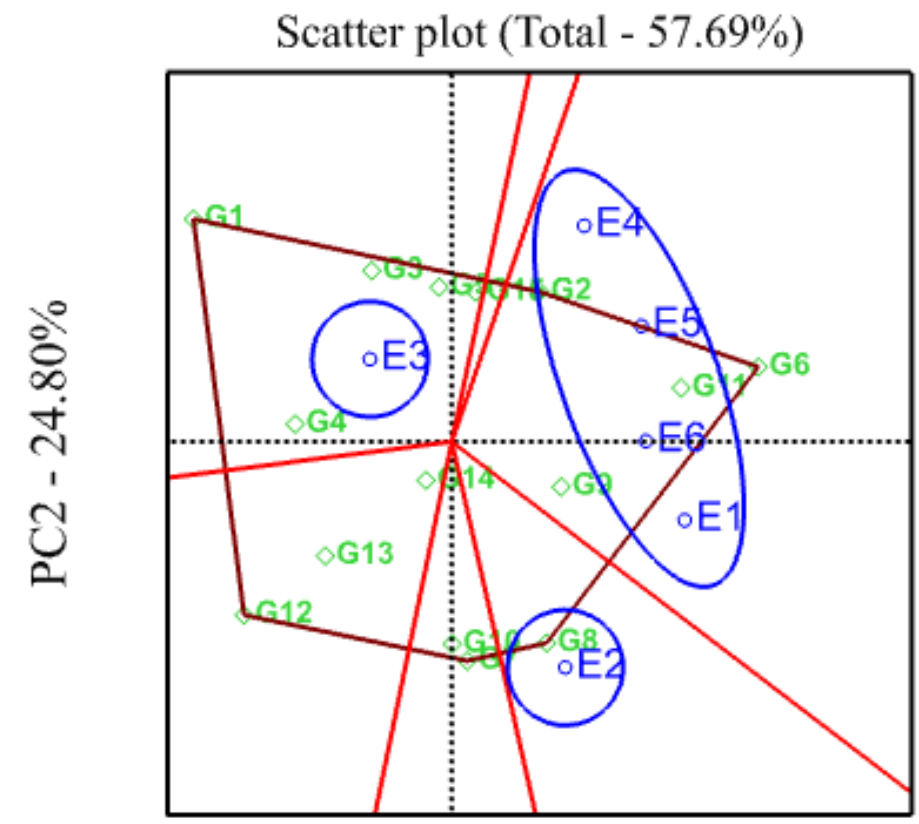

PC1 $-32.89 \%$

Figure 2. "Which-won-where" and clustering of mega-environments. 


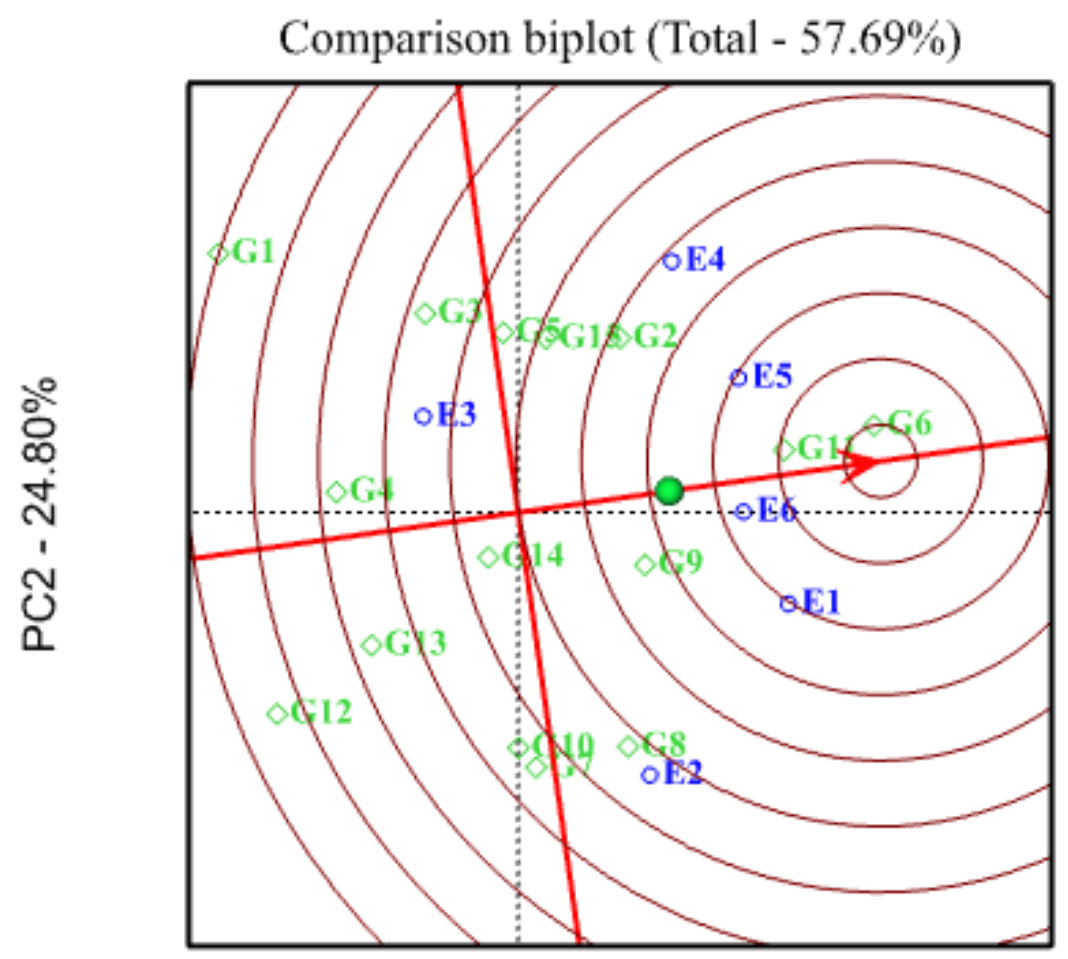

PC1 - 32.89\%

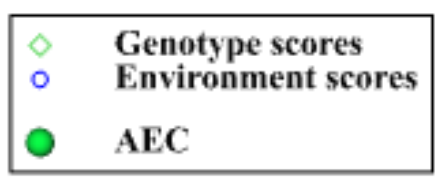

Figure 3. Visualization of ideal malt barley genotype.

ideal genotypes (Figure 3), as well as the discriminating power and representativeness of environments (Figure 4) were plainly plotted in GGE biplot graph using PC1 and PC2 scores.

\section{Performance and stability of genotypes}

Grain yield performance and stability of malt barley genotypes were examined using an Average Environment Coordination (AEC) method (Yan, 2002). Accordingly, the GGE biplot displayed malt barley genotypes based on their mean grain yield and GEI. AEC-abscissa, a singlearrowed line, was drawn from the origin of the biplot to the center of the small circle called average environment. The arrow on the AEC-abscissa axis points to the direction of high yielding genotypes (Yan et al., 2007). $\mathrm{G}_{6}, \mathrm{G}_{11}, \mathrm{G}_{2}, \mathrm{G}_{9}$, $G_{8}$ and $G_{15}$ yielded above average grain yield in descending order and thus plotted either at quadrant 1 or quadrant 4 of the GGE biplot graph, indicating their adaptability to terminal moisture stress environments of North Wollo. The rest of the genotypes, on the other hand, yielded below average and hence plotted either at quadrant 2 or quadrant 3 , showing their poor adaptability to the testing environments (Figure 1, Table 4).

The AEC ordinate, a double arrowed line drawn from the GGE biplot origin perpendicular to the AEC-abscissa, was used to estimate genotypic contribution to GEl. It measures phenotypic stability of genotypes for grain yield under diverse environments (Yan et al., 2007). $\mathrm{G}_{1}, \mathrm{G}_{8}, \mathrm{G}_{7}$ and $G_{10}$ exhibited high PC2 scores (absolute value), referring their sensitivity to environmental variability (Figure 1). On the other hand, $\mathrm{G}_{11}$ and $\mathrm{G}_{6}$ were plotted near the AEC-abscissa, indicating their relative stability to variable environments. Therefore, $G_{6}$ and $G_{11}$ yielded above average grain yield and possessed insignificant environmental interaction. Grain yield is the major economic trait in variety development. Genotypic yield performance inconsistency across locations and seasons is undesirable and hence, plant breeders explore high 


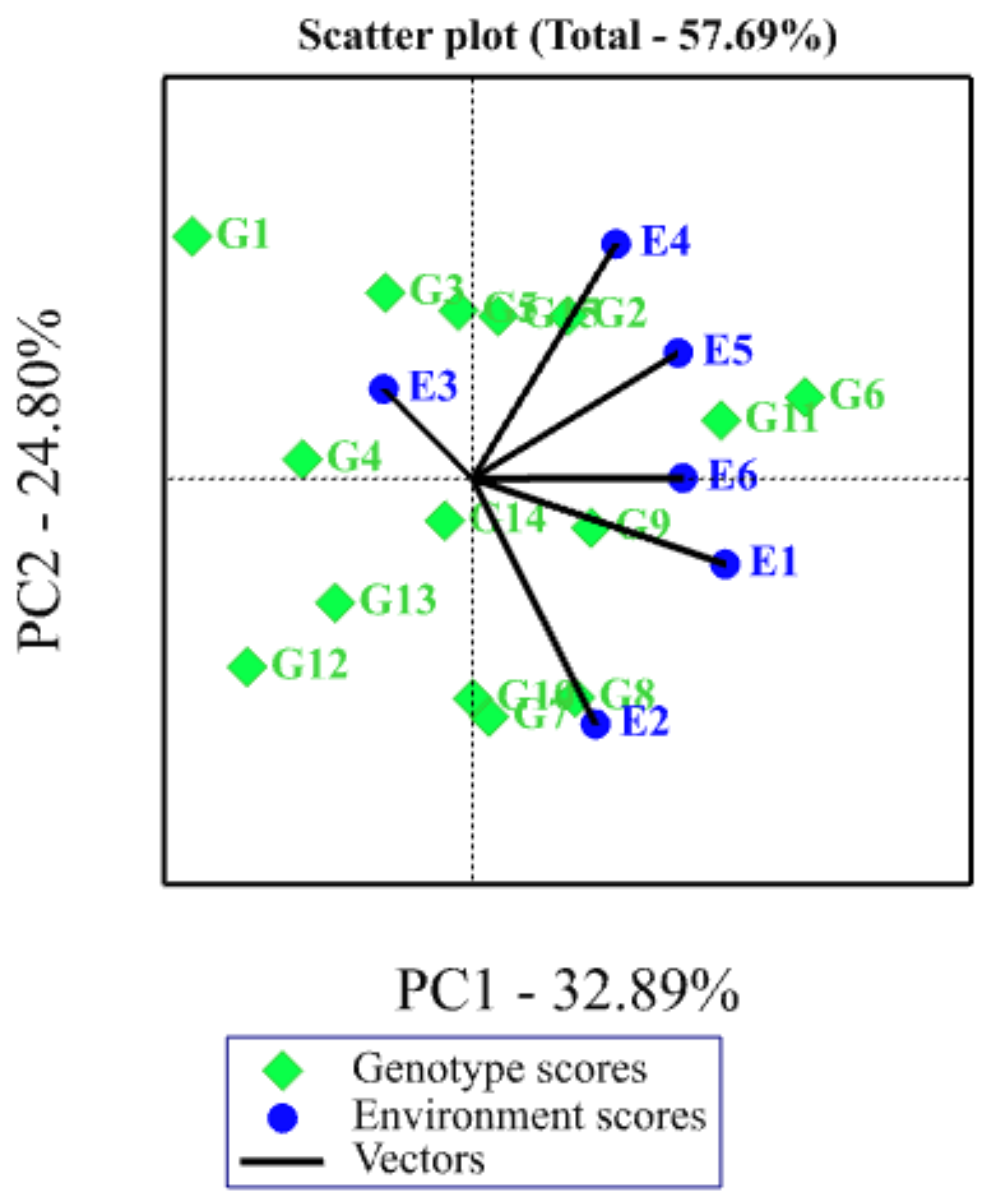

Figure 4. Visualization of discriminating and representative environments.

yielding and environmentally stable genotype (Kang, 2002). Stable genotypes are regarded genetically elastic. Such genotypes have wide adaptability regardless of environmental variability. From this study, $\mathrm{G}_{6}$ and $\mathrm{G}_{11}$ were found high yielding and stable malt barley genotypes suitable for moisture stressed environments of North Wollo.

\section{"Which- Won-Where" and clustering of environments}

Graphical representation of genotypes and environments using GGE biplot helps to visualize the winning genotype at a specific environment. The polygon was formed by connecting the vertices of genotypes located farthest away from the biplot center (Yan et al., 2007). In this study, hexagon was formed by connecting the vertices of $\mathrm{G}_{6}, \mathrm{G}_{8}$, $G_{2}, G_{7}, G_{12}$ and $G_{1}$. Lines were perpendicularly drawn from the origin of the biplot to the polygon's side and divided the polygon into seven sectors, forming three clusters for malt barley production (Figure 2). Cluster-I comprised $\mathrm{E}_{1}, \mathrm{E}_{6}, \mathrm{E}_{5}$ and $\mathrm{E}_{4} . \mathrm{G}_{6}$, which possessed the maximum PC1 score, was plotted at the far right of the vertex of the polygon along with $E_{1}, E_{6}, E_{5}$ and $E_{4}$. Thus, $G_{6}$ is the winning malt barley genotype at this mega-environment. $E_{2}$ and $E_{3}$ fall into two separate environments, showing their distinctiveness to the rest of the testing environments, forming cluster-II and cluster-III, respectively. $\mathrm{G}_{8}$ was plotted with $E_{2}$, revealing $G_{8}$ was the winner genotype at cluster-II. On the other hand, $G_{1}$ was plotted with $E_{3}$ at the far left end of the vertex of the polygon, indicating its poor performance compared to the testing environments. $E_{3}$ and $E_{6}$ represented the highland (altitude $>3000$ meters above sea levels) and frost-prone barley growing areas of North Wollo. The high elevation, poor soil fertility and low temperature (sometimes $\angle 0^{\circ} \mathrm{C}$ at the critical grain filling period at Estayish testing site $\left(E_{3}\right.$ and $\left.E_{6}\right)$, particularly at $\mathrm{E}_{3}$ contributed for huge environmental variations (Table 1).

Seasonal variation is very difficult to capture and thus complicates varietal selection. Identifying cold tolerant, environmentally stable and high yielding genotypes could minimize the risks associated with seasonal variation. GGE biplot analysis was carried-out to single-out ideal malt barley genotype at terminal moisture stressed environments of Wollo. Therefore, the "Which-WonWhere" GGE biplot analysis yet again unveiled $\mathrm{G}_{6}$ and $\mathrm{G}_{11}$ 
as the winner malt barley genotypes at the megaenvironment. In agreement with the current finding, Tonk et al. (2011), Farshadfar et al. (2013) and Karimizadeh et al. (2013) used GGE-biplot technique to cluster megaenvironments, to identify ideal environments and the winning genotype for each mega-environment.

\section{Ideal malt barley genotypes}

Stable and high yielding genotype is regarded as an ideal genotype, which is represented by the concentric circle (Yan et al., 2007). In reality, an ideal genotype may not exist but it can be used as a benchmark for genotypic evaluation (Yan and Tinker, 2006). The closer a genotype to the concentric circle is the more favorable it is. $\mathrm{G}_{6}$ was plotted near the concentric circle followed by $G_{11}$ (Figure 3 ), denoting their yielding potential and relative stability to the fluctuating seasonal and location variability. Therefore, $\mathrm{G}_{6}$ and $\mathrm{G}_{11}$ were found desirable malt barley genotypes for moisture stressed areas of North Wollo. Similar to the current finding, Tonk et al. (2011) and Farshadfar et al. (2013) identified ideal genotypes using GGE biplot analysis technique for maize and chickpea, respectively.

\section{Discriminating and representative environments}

GGE biplot also plotted the testing environments based on their discriminating power and representativeness to effectively identify superior genotypes for megaenvironments. Environments possessing long vectors had an excellent discriminating power and thus regarded as valuable testing environments to stringently screen genotypes based on their genetic performance. On the other hand, environments with short vector length have poor discriminating power (Yan et al., 2007). In this study, all the testing environments except $\mathrm{E}_{3}$ exhibited relatively long vectors, explaining their excellent discriminating power. No clear genetic variation was observed among the tested malt barley genotypes for grain yield due to severe frost incidence at $E_{3}$ (Estayish-2013). Thus, $E_{3}$ failed to differentiate the testing malt barley genotypes according to their genetic potential. Thus, $E_{3}$ is not informative environment to clearly sort-out malt barley genotypes based on their genetic potential.

GGE biplot also helps to identify representative environments for the mega-environment. $A$ test environment possessing small angle with AEC-abscissa is the most representative environment of the megaenvironments than those with larger angle (Farshadfar et al., 2013; Karimizadeh et al., 2013). E6 displayed small angle with $A E C$-abscissa, indicating its representativeness to the mega-environment for malt barley grain yield production. An "ideal" test environment, which actually might not exist in reality, should be both discriminating of the genotypes and representative to the mega-

environment (Yan et al., 2007). $E_{6}$ had long vector with small angle from abscissa is the most desirable environ- ment to examine malt barley genotypes for grain yield (Figure 4). Therefore, initial evaluation of malt barley genotypes should be done at $\mathrm{E}_{6}$ (Estayish testing site) to screen large number of malt barley accessions and then advanced screen should be carried-out at $\mathrm{E}_{2}$ (Kon) and $\mathrm{E}_{4}$ (Geregera) to precisely cull-out genotypes with undesirable traits. Amount, distribution, onset and cessation of rainfall significantly varied across seasons. Because of the presence of huge seasonal variation in the testing locations, malt barley genotypes should be tested at least for two seasons. Solonechnyi et al. (2015) and Karimizadeh et al. (2013) reported the efficiency of GGE biplot technique discriminating and representative environments for spring barley and lentil breeding and selection, respectively.

\section{Conclusion}

In this study, significant variation was observed among malt barley genotypes for grain yield. $\mathrm{G}_{6}, \mathrm{G}_{11}$ and $\mathrm{G}_{2}$ were found the best malt barley genotypes that yielded above average. Moreover, malt barley production was significantly affected by seasonal and location variations. Combined ANOVA depicted highly significant $(p<0.01)$ variation among genotypes $(G)$, genotype by year $(G \times Y)$ and genotype by location $(G \times L)$ interaction for grain yield. The presence of $G \times Y$ and $G x L$ interaction revealed differential responses of genotypes across years and locations, respectively. Of the total variations, year contributed the maximum sum of squares, indicating the presence of huge seasonal variation. Variation in onset, distribution and termination of rainfall between the two cropping seasons, as well as frost incidence at $E_{3}$ contributed unrepeatable huge seasonal variation. Compared to 2013 cropping season, 2014 was a good season for malt barley production due to the relative fair rainfall distribution across the growing season. However, it is impossible to capture seasonal variations and it is impractical to develop varieties for a season. Significant GxYXL jeopardizes selection and reduces its efficiency. Therefore, identifying stable and high-yielding genotype is imperative to minimize genotypic yield inconsistencies at variable environments.

From this study, $G G E$ biplot identified $G_{6}$ and $G_{11}$ as high yielding and stable genotypes. $G_{6}$ and $G_{11}$ were less sensitive to unpredictable environmental variations and recommended for terminal moisture stressed environments of North Wollo. It could be concluded that both $\mathrm{G}_{6}$ and $\mathrm{G}_{11}$ are agronomically superior and stable malt barley genotypes. Therefore, these genotypes should be introduced to the client farmers so as to improve production and productivity of malt barley under terminal moisture stressed environments of North Wollo.

\section{CONFLICT OF INTEREST}

The authors declare that they have no conflict of interest. 


\section{REFERENCES}

Agyeman, A., Parkes, E., \& Peprah, B. B. (2015). AMMI and GGE biplot analyses of root yield performance of cassava genotypes in forest and coastal ecologies. International Journal of Agricultural Policy and Research, 3(3), 122-132.

Akçura, M., Kaya, Y., \& Taner, S. (2009). Evaluation of durum wheat genotypes using parametric and nonparametric stability statistics. Turkish Journal of Field Crops, 14(2), 111-122.

Bantayehu, M. (2013). Study on malting barley genotypes under diverse Agroecologies of north western Ethiopia. African Journal of Plant Science, 7(11), 548-557.

Central Statistical Agency of the Federal Democratic Republic of Ethiopia (CSA) (2016). Agricultural Sample Survey 2015/2016, Statistical Bulletin 584, Addis Ababa.

d Steel, R. G., \& Torrie, J. H. (1986). Principles and procedures of statistics: a biometrical approach: McGraw-Hill publ. Company.

Ding, M., Tier, B., \& Yan, W. (2007). Application of GGE biplot analysis to evaluate Genotype (G). Environment (E) and GxE interaction on $P$. radiata: a case study. $15 p$.

Fan, X. M., Kang, M. S., Chen, H., Zhang, Y., Tan, J., \& Xu, C. (2007). Yield stability of maize hybrids evaluated in multienvironment trials in Yunnan, China. Agronomy Journal, 99(1), 220-228.

Farshadfar, E., Rashidi, M., Jowkar, M. M., \& Zali, H. (2013). GGE Biplot analysis of genotype $\times$ environment interaction in chickpea genotypes. European Journal of Experimental Biology, 3(1), 417-423.

Gashaw, A., Mohammed, H. \& Singh, H., (2010). Genotypic variability, heritability, genetic advance and associations among characters in Ethiopian Durum Wheat (Triticum durum Desf.) Accessions. East African Journal of Sciences, 4(1), 2733.

Ilker, E., Geren, H., Unsal, R., Sevin, I., Aykuttonk, F., \& Tosun, M. (2011). AMMI-Biplot analysis of yield performances of bread wheat cultivars grown at different locations. Turkish Journal of Field Crops, 16(1), 64-68.

Ilker, E., Kocaturk, M., Kadiroglu, A., Altinbas, M., Yildirim, A., Ozturk, G., \& Yildiz, H. (2018). Stability analysis for double cropping in soybeans [(Glycine max L.) Merrill]. Turkish Journal of Field Crops, 23(2), 80-84.

Kadhem, F., \& Baktash, F. (2016). AMMI analysis of adaptability and yield stability of promising lines of bread wheat (Triticum aestavum L.). The Iraqi Journal of Agricultural Science, 47(7special issue), 35-43.
Kang, M. S. (1997). Using genotype-by-environment interaction for crop cultivar development. Advances in Agronomy, 62, 199252.

Kang, M. S. (2002). Quantitative genetics, genomics, and plant breeding. Wallingford, UK, CABI

Karimizadeh, R., Mohammadi, M., Sabaghni, N., Mahmoodi, A., Roustami, B., Seyyedi, F., \& Akbari, F. (2013). GGE biplot analysis of yield stability in multi-environment trials of lentil genotypes under rainfed condition. Notulae Scientia Biologicae, 5(2), 256-262.

Oliveira, E., Freitas, J. \& Jesus, O. (2014). AMMI analysis of the adaptability and yield stability of yellow passion fruit varieties. Scientia Agricola, 71(2), 139-145.

Solonechnyi, P., Vasko, N., Naumov, A., Solonechnaya, O., Vazhenina, O., Bondareva, O., \& Logvinenko, Y. (2015). GGE biplot analysis of genotype by environment interaction of spring barley varieties. Zemdirbyste-Agriculture, 102(4), 431-436.

Tonk, F. A., Ilker, E., \& Tosun, M. (2011). Evaluation of genotype $x$ environment interactions in maize hybrids using GGE biplot analysis. Crop Breeding and Applied Biotechnology, 11(1), 0109.

Yan, W. (2002). Singular-value partitioning in biplot analysis of multi-environment trial data. Agronomy Journal, 94(5), 990996.

Yan, W., \& Hunt, L. (2001). Interpretation of genotypex environment interaction for winter wheat yield in Ontario. Crop Science, 41(1), 19-25.

Yan, W., \& Tinker, N. (2006). Biplot analysis of multi-environment trial data: Principles and applications. Canadian Journal of Plant Science, 86(3), 623-645.

Yan, W., Kang, M., Ma, B., Woods, S., \& Cornelius, P. (2007). GGE biplot vs. AMMI analysis of genotype-by-environment data. Crop Science, 47(2), 643-653. 